Research Article

\title{
Damage Evolution of Sandstone under Constant-Amplitude Cyclic Loading Based on Acoustic Emission Parameters and Resistivity
}

\author{
Kui Wang $\mathbb{D},{ }^{1}$ Zhengting Xia $\mathbb{D}^{1},{ }^{1}$ Zhen Huang $\mathbb{D},^{2}$ and Xue Li $\mathbb{D}^{1}$ \\ ${ }^{1}$ Engineering Research Center of Diagnosis Technology of Hydro-Construction, Chongqing Jiaotong University, \\ Chongqing 400074, China \\ ${ }^{2}$ Chongqing Panlong Pumped Storage Power Station Co. Ltd., Chongqing 401420, China
}

Correspondence should be addressed to Kui Wang; anhuiwk@163.com

Received 26 May 2021; Revised 2 July 2021; Accepted 6 August 2021; Published 12 August 2021

Academic Editor: Rotana Hay

Copyright (C) 2021 Kui Wang et al. This is an open access article distributed under the Creative Commons Attribution License, which permits unrestricted use, distribution, and reproduction in any medium, provided the original work is properly cited.

In the real environment, besides static load, rock is more affected by cyclic load. There is a large difference in the mechanical properties exhibited by rocks under cyclic and static loading. Therefore, it is particularly necessary to investigate the mechanical characteristics of rock subjected to cyclic loading. These parameters of rock, acoustic emission (AE) and resistivity, are both sensitive to the failure process of rock, and they are complementary to the different stages of rock damage. Therefore, in this paper, the $\mathrm{AE}$ characteristics and resistivity properties of sandstone subjected to constant-amplitude cyclic loading and unloading were experimentally investigated using a typical sandstone in Chongqing. The same three-stage pattern was found for the AE evolution of sandstones during constant-amplitude cyclic loading. Initial evolution stage: the rock deformation is fast with strong changes in the AE signal. The rock deformation developed slowly while the changes of the AE signal were stable in the constant velocity evolution stage. The rock deformation developed dramatically while the AE signal became more intense in accelerated evolution stage. The change in resistivity is characterized by a rapid decrease during the loading stage and a rapid rebound during the unloading stage. Overall, from the beginning of the cycle to the end of the cycle, the resistivity of the sandstone showed a general trend of gradual decrease, until the sudden increase in resistivity at the time of damage. Finally, a damage model based on AE parameters and resistivity was constructed by combining damage mechanics.

\section{Introduction}

Rock mass is a discontinuous medium with a complex internal structure. Many studies $[1,2]$ have shown that the phenomenon of particle crushing often occurs in conjunction with rock particle compaction, and a number of experimental methods have been carried out to analyze the crushing behaviour of rock particles. Ma et al. [3, 4] used laboratory, theoretical, and field studies followed by experimental data to calculate and analyze the evolution of the deformation behaviour of gangue grains during compression tests. Alnedawi et al. [5] monitored the effect of loading frequency on rock deformation characteristics by using repeated loading triaxial tests.

In addition, there are also a series of studies on the evolution of rock damage. Hu et al. [6] performed triaxial tests on granular rocks under cyclic stress paths and discussed the linear evolution of the plastic work with respect to the critical state. Ghebi and Hedaya [7] investigated the ultrasonic properties, such as longitudinal velocity, principal frequency, and transmission amplitude, during compressional deformation of granular quartzitic rocks. Rock's stability is affected by many natural conditions and human factors. Furthermore, in practical engineering applications, the rock mass is often subject to cyclic loading, for example, coal rock exhibits different damage patterns under cyclic disturbance and early backfill liquefaction due to cyclic loading conditions such as far-field mine blasting, rock blasting, and earthquakes. Under the action of cyclic loading, rock damage gradually accumulates until the final appearance of fatigue degradation characteristics, which have a negative impact on the stability of the project and increase 
the risk of engineering safety. Therefore, the study of rock damage law under constant-amplitude cyclic loading has important practical value in engineering.

As an elastic wave, $\mathrm{AE}$ is produced by the damage of rock itself, and the rock is bound to be accompanied by the closure of pores and the initiation and propagation of microcracks in the process of loading. Therefore, the damage and failure process of rock is bound to be accompanied by the generation of $\mathrm{AE}$ signals, which can represent the damage evolution of rocks. The phenomenon of AE activity in rock during compression was first found in the 1930s [8]. After years of research by scholars [9-12], the application of the $\mathrm{AE}$ method in rock materials is becoming more and more mature. Rodríguez et al. [13] characterized the fracture mode of marble and granite in a radial compression test by $\mathrm{AE}$ experiment and lithofacies analysis, so that the main cracking areas in rock samples and their changes in the test process can be visualized. Lei et al. [14] researched the damage evolution of several common lithologies under differential compression using detailed AE data. Ou et al. [15] conducted graded loading tests on marble under different stress paths and investigated the $\mathrm{AE}$ characteristics and the changing trend of loading-unloading response ratio in the deformation and failure process of marble under variable stress paths. Zhao et al. [16] used the AE system to study the uniaxial compression process of red sandstone specimens under different water contents and analyzed the characteristics of special stress and the evolution of AE (wide and narrowband) parameters in the deformation and failure process of specimens. Jiang et al. [17] analyzed the properties of $\mathrm{AE}$ during fatigue injuries of red sandstone, divided the axial deformation process into three stages and the transverse deformation process into two stages, and discussed the rationality of the damage variable theory according to axial strain.

As one of the inherent characteristics of rock, the resistivity is a necessary condition to study its microstructure and engineering mechanical properties, which can usually reflect the basic physical characteristics of rock. In practical engineering, people usually detected the geological conditions of engineering rock based on resistivity characteristics [18]. It was not until 1942 that the study of the resistivity properties of rocks was gradually developed on the basis of Archie's law [19-22]. Brace and Orange [23] analyzed the variation law of resistivity during rock failure through an indoor resistivity test and believed that the change of rock volume and porosity was the fundamental factor for the change of resistivity. Zhang et al. [24] studied sandstone under different thermal damage and tested the resistivity of sandstone at different temperatures, indicating that monitoring resistivity is a good method for detecting thermal damage to rocks. Wang et al. [25] explained the variation characteristics of rock resistivity from the theoretical level combined with the typical rock expansion phenomenon. At the same time, the damage variable based on resistivity was established by the analogy method, and the resistivity ratio coefficient was introduced to characterize the damage degree of overburden in coal mine goaf. In addition, $\mathrm{Wu}$ et al. [26] obtained the theoretical relationship between porosity and rock resistivity based on Archie's formula. In general, the closure of pores in rock materials, changes in volume, and the expansion of microcracks in response to external forces affect the electrical conductivity of rocks. Therefore, it is possible to judge the evolution of damage to rocks by the pattern of changes in resistivity and thus infer the mechanical properties of rocks for engineering construction.

To sum up, although some studies had been conducted on the correlation between $\mathrm{AE}$ characteristics and rock resistivity, there has been relatively little research into the parameters of wave-electric characteristics of rocks under cyclic stress and the integrated use of the wave-electric test to investigate the evolution of damage deformation in rocks. In a previous study [27], under different test conditions, the two characteristics of $\mathrm{AE}$ and resistivity of sandstone were investigated, such as different stress amplitudes and different loading frequencies, using sandstone as the object of study. Furthermore, different saturation levels were tested and the evolution law of $\mathrm{AE}$ was found. Based on existing studies of the $\mathrm{AE}$ and resistivity evolution of sandstones, this paper further studies the damage evolution process of sandstone under constant-amplitude cyclic loading and deeply analyzes the relationship among sandstone $\mathrm{AE}$ parameters and resistivity parameters and damage accumulation. Therefore, according to the AE parameters and the resistivity parameters, the damage evolution model of sandstone under cyclic loading was established.

\section{Test Device and Method}

Figure 1 shows the self-designed synchronous testing device of $\mathrm{AE}$, resistivity, and stress employed in the tests. The loaded test system used the RMT-301 rock mechanics test system, and a fixed device of the AE sensor was designed. The four sensors had been installed on the surrounding surface of the sandstone specimens, and the coupling agent was applied to ensure that the sandstone specimen is in good contact with the sensor. Finally, the position of the AE sensor was fixed by tightening the screws. In the experiment, as shown in Figure 2, the M300 data acquisition system was used for the resistivity test, and the SAEU2S AE system was used for the AE test.

2.1. Sandstone Sample Preparation. The samples used in this experiment were all derived from the same area of Chongqing sandstone rock samples. The sandstone specimens were obtained by the wet processing method and drilling, accurately processing into $\Phi 50 \mathrm{~mm} \times 100 \mathrm{~mm}$ standard cylindrical specimens, and the flatness error of the two bottom surfaces was not more than $0.02 \mathrm{~mm}$, as shown in Figure 3. The height, wave velocity, mass, and diameter of the specimens are measured. Furthermore, the sandstone specimens with the closest density, geometry, and wave speed were grouped and numbered to reduce the dispersion of test results due to individual differences. For each working condition, three samples were tested to ensure the accuracy of the results. 


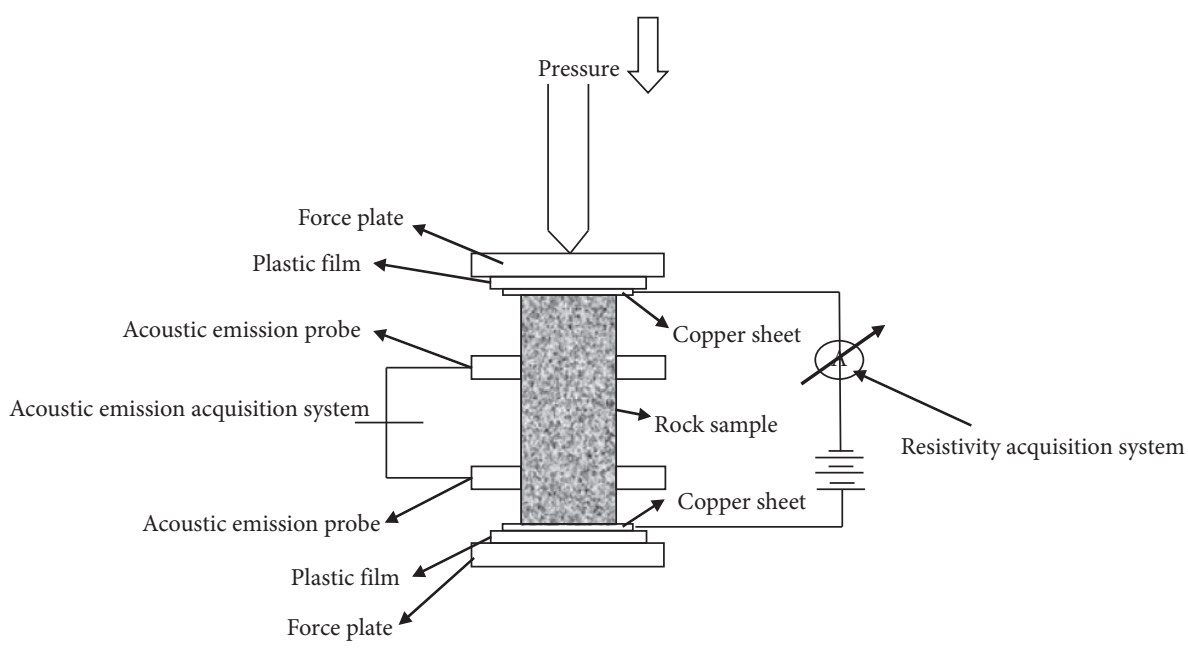

Figure 1: Test system design.

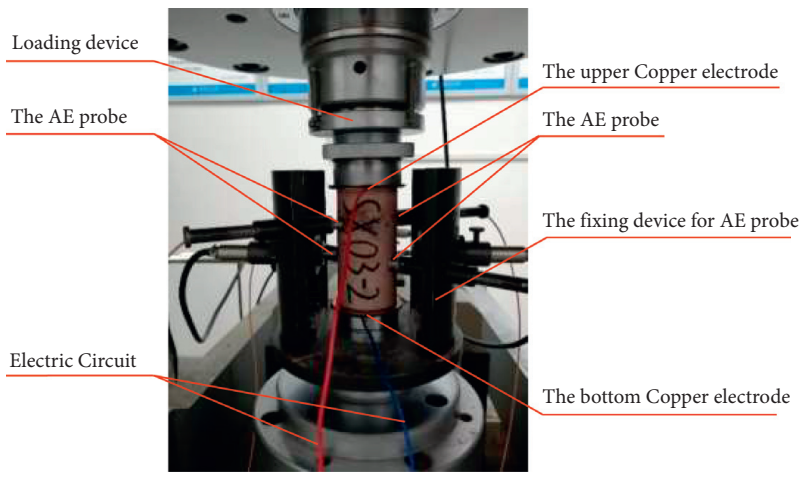

Figure 2: Stress-AE-resistivity synchronous testing device.

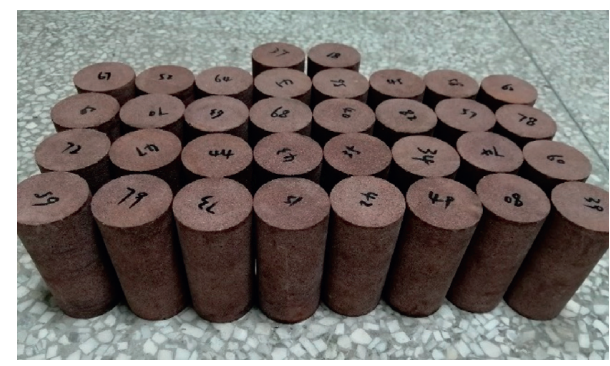

FIGURE 3: Sandstone specimen.

Through the analysis of the sandstone composition, the sandstone studied in the thesis was mainly made up of quartz, plagioclase, and potash feldspar, with mica, calcareous, and iron cuttings as minor components. The cement is mainly made up of argillaceous minerals, calcite, and dolomite with the least content of pyrite. The specific component content is shown in Table 1 .

2.2. Loading Equipment. The rock mechanical test system, RMT-301, developed by Wuhan Institute of Geotechnical Mechanics, Chinese Academy of Sciences, was used in this rock loading test. The system is a multifunctional electrohydraulic servo testing machine that can be controlled by a computer. It is a unique four-in-one function system, which has the advantages of convenient operation, good control performance, high automation, and high stiffness. It can be used for uniaxial, triaxial, shear, and tensile tests.

\subsection{Measuring Equipment and Parameters}

2.3.1. Acoustic Emission Test Instrument. AE test adopts the SAEU2S multichannel AE signal measurement system manufactured by Beijing Shenghua Science and Technology Co., Ltd., which had 24 parallel detection channels and can simultaneously measure multichannel signals, as shown in Figure 4 . In the process of signal acquisition, the waveform of each channel $\mathrm{AE}$ signal and various $\mathrm{AE}$ characteristic parameters could be displayed in real time, which could meet the needs of various field detection and scientific research. The main amplifier of the AE test device is $40 \mathrm{~dB}$, the voltage threshold was set to $45 \mathrm{~dB}$, the resonant frequency of the sensor was $20 \sim 400 \mathrm{kHz}$, and the sampling frequency was $1 \times 10^{7}$ times/s. At the same time, the ambient noise is needed to be standardized before the experiment to minimize the influence of noise on the test data.

2.3.2. Resistivity Test Instrument. Resistivity test adopted M300 series data acquisition/switching system produced by Beijing Puyuan Precision Electric Technology Co., Ltd, as shown in Figure 5. This system combined precise measurement function with flexible signal connection function, which could collect voltage, current, resistance, temperature, and various sensor signals and provide long-term measurement and recording of multiple test points and various signals. In this experiment, the bipolar method was carried out to measure the resistance of the sandstone specimen. Then, the resistivity $\rho$ of the sandstone specimen was indirectly obtained according to the formula $\rho=R(S / L)$. To ensure the dependability of the measurement data, copper sheets with good conductivity should be placed on both ends of the specimen. At the same time, a plastic gasket should be placed on both ends of the end face to play the role of 
TABLE 1: Sand rock composition.

\begin{tabular}{|c|c|c|c|c|c|c|c|c|}
\hline \multicolumn{4}{|c|}{ Debris (\%) } & \multicolumn{3}{|c|}{ Cement (\%) } & \multirow{3}{*}{$\begin{array}{c}\begin{array}{c}\text { Cementation } \\
\text { type }\end{array} \\
\text { Porosity }\end{array}$} & \multirow{2}{*}{$\begin{array}{c}\text { Granularity }(\mathrm{mm}) \\
0.01-0.15\end{array}$} \\
\hline Quartz & $\begin{array}{c}\text { Plagioclase/potassium } \\
\text { feldspar }\end{array}$ & Schist/mica & Calcareous/iron & Argillaceous & Dolomite & Pyrite & & \\
\hline 57 & 23 & 3 & 6 & 8 & 2 & 1 & & \\
\hline
\end{tabular}

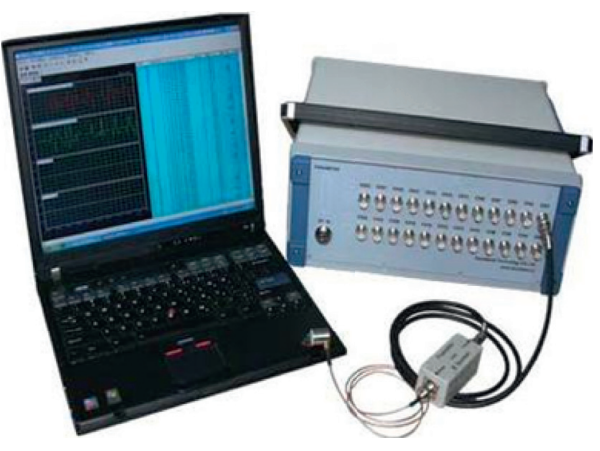

FIgURE 4: SAEU2S multichannel acoustic emission signal measurement system.

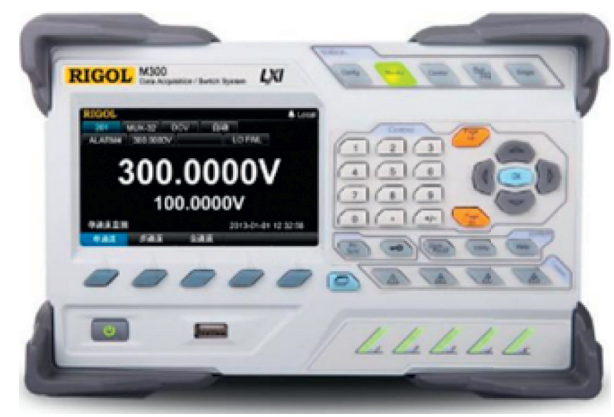

Figure 5: M300 series data acquisition/switching system.

insulation, and a certain amount of graphite powder should be applied to the ends of the sandstone specimen to increase the conductivity of the rock.

2.4. Test Method. Firstly, uniaxial compression tests of sandstone samples all take axial force as the control parameter. To maintain the consistency before and after the test, in the uniaxial compression test, the same axial force as the constant-amplitude cyclic loading test was used as the control parameter with $0.5 \mathrm{kN} / \mathrm{s}$ of the average loading rate. Finally, six specimens were selected for the test. According to the test results, the compressive strength and variance of specimens are shown in Table 2.

The lower limit stress value $\sigma_{\min }=12.554 \mathrm{MPa}$ and the upper limit stress value $\sigma_{\max }=53.355 \mathrm{MPa}$ for the cyclic load used in this study, so the average stress and amplitude are, respectively, $32.955 \mathrm{MPa}$ and $20.401 \mathrm{MPa}$.

As shown in Figure 6, the equal amplitude cyclic test uses axial force as the control variable and the test was conducted in two stages. In the first stage, the axial stress was loaded continuously from zero to the average stress value $\left(\sigma_{\max }+\sigma_{\min }\right) / 2$ at a rate of $0.5 \mathrm{kN} / \mathrm{s}$. In the second stage, the cyclic loading was applied from the average stress value until the fatigue damage occurred in the sandstone specimen. Because the $\mathrm{AE}$ characteristics of sandstone specimens under the action of different stress amplitudes are relatively similar, the yield strength of sandstone will not be exceeded when the stress magnitude is below $85 \%$ of the compressive strength. So, the loading waveform was sinusoidal, and the frequency was $0.2 \mathrm{~Hz}$, of which the upper-stress limit $\sigma_{\text {max }}$ was $85 \%$ of the uniaxial compressive strength, and the lowerstress limit $\sigma_{\min }$ was $20 \%$ of the uniaxial compressive strength. The cyclic loading tests of 3 specimens were carried out under this condition.

\section{Test Results and Analysis}

The number of $\mathrm{AE}$ ringing refers to the number of oscillations caused by the oscillating wave generated by the $\mathrm{AE}$ signal crossing the voltage threshold, which has been widely used in the activity evaluation of AE. The number of acoustic emission rings produced per unit time in a rock sample can reflect the state of damage and deformation of the internal structure of the sample when subjected to cyclic stress. The more the number of $\mathrm{AE}$ ringing counts in unit time, the more serious the damage of the rock sample. On the contrary, the damage degree of rock samples was lighter.

Therefore, this paper mainly explores the AE characteristics of sandstone specimens by AE ring number. Based on the experimental results, as shown in Figure 7, the axial force and ring number-time curves of two representative sandstone specimens were plotted.

At present, the characteristic parameter method is widely used in processing AE signals [28]. The AE characteristic parameters contain a lot of information about the material damage evolution process, and the characteristic parameter method is to reflect the characteristics of AE signals by analyzing and processing several simplified waveform characteristic parameters. From the AE evolution diagram of sandstone damage evolvement process under constantamplitude cyclic loading, it is possible to find that the $\mathrm{AE}$ intensity of two sandstone specimens was different under the same stress level based on cyclic loading. The AE intensity of specimen 1 was greater than that of specimen 2 , which was due to the heterogeneity of the specimen. Rock was heterogeneous material, its internal structure characteristics of different rocks were different, and the mechanical properties were different.

During the cyclic loading phases, the evolution pattern of the AE signal closely matches the three-stage law of rock fatigue deformation proposed by Ge et al. [29, 30]. During the first few cycles, the original cracks and weak structural surfaces in the specimen were destroyed, the degree of 
TABLE 2: Results of uniaxial compression test.

\begin{tabular}{lcc}
\hline No. & Compressive strength $(\mathrm{kN})$ & Average compressive strength $(\mathrm{kN})$ \\
\hline DZ01 & 116.880 & \\
DZ02 & 123.600 & \\
DZ03 & 127.050 & 120.245 \\
DZ04 & 125.100 & \\
DZ05 & 119.670 & \\
DZ06 & 109.170 & \\
\hline
\end{tabular}

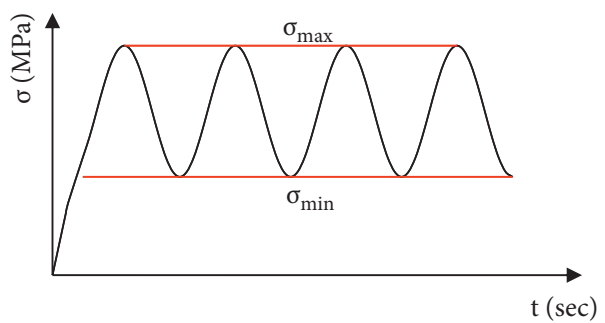

FIGURE 6: Loading loop path.

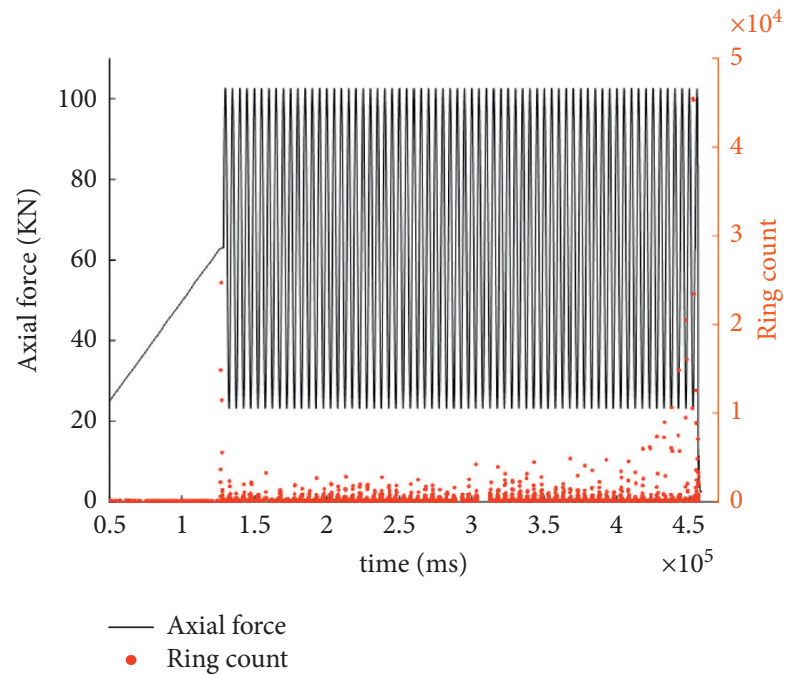

(a)

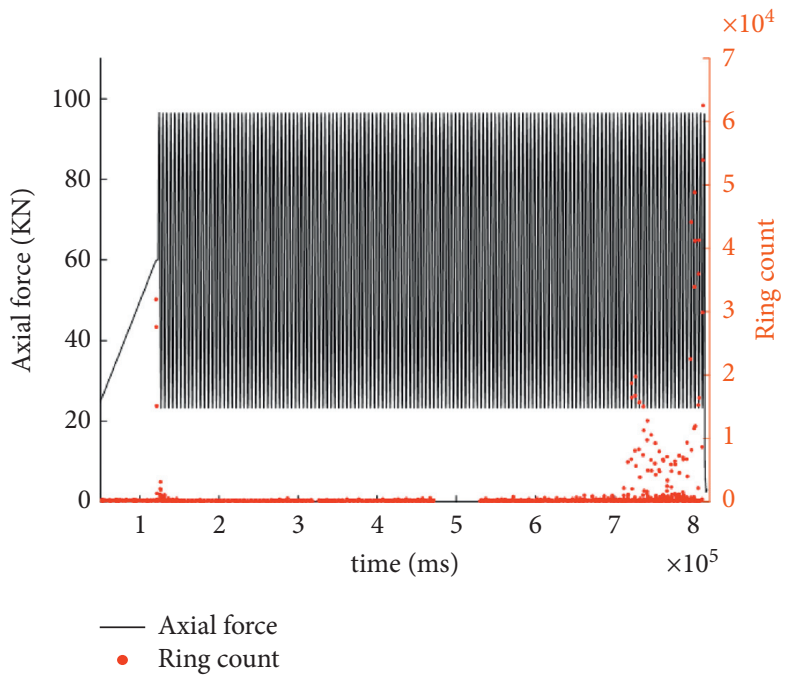

(b)

FIgURE 7: Evolution law of acoustic emission: (a) acoustic emission evolution law of specimen 1; (b) acoustic emission evolution law of specimen 2 .

sandstone deformation was rapid, the AE activity evolved strongly, and the number of $\mathrm{AE}$ vibrations was high. Then, entering the stage of constant velocity development, as can be seen from the AE local magnification diagram, where the $\mathrm{AE}$ signal of essentially the same magnitude is present in each cycle, the evolution of the AE activity diminishes and the number of rings decreases, indicating that the upper stress had reached the yield strength of the rock and therefore a small amount of plastic damage occurs in each cycle. Finally, in the accelerated damage phase, the degree of deformation of the rock suddenly increases and its strain reaches the ultimate deformation of the rock in a few cycles. The macroscopic fracture was penetrated, and the rock was destroyed. It can be seen that the evolution of AE activity was suddenly enhanced, and the number of ringing counts increased exponentially, which well reflects the destruction process of the rock material during cyclic loading. Furthermore, most of the AE signals occur near the upper-stress limit, indicating that the upper-stress limit was more sensitive to the AE signals from the rock [31].

At the same time, the force-time and resistivity-time curves of specimens were drawn, respectively, according to the test results, as shown in Figure 8, to investigate the variation law of sandstone resistivity under constant-amplitude cyclic loading.

The resistivity of the sandstone loaded in equal amplitude cycles follows a basically similar pattern to the loading path as can be seen from Figure 6. During the loading stage, due to the heterogeneity of rock specimens, there were many microcracks and pores in the rock specimen, the stress 


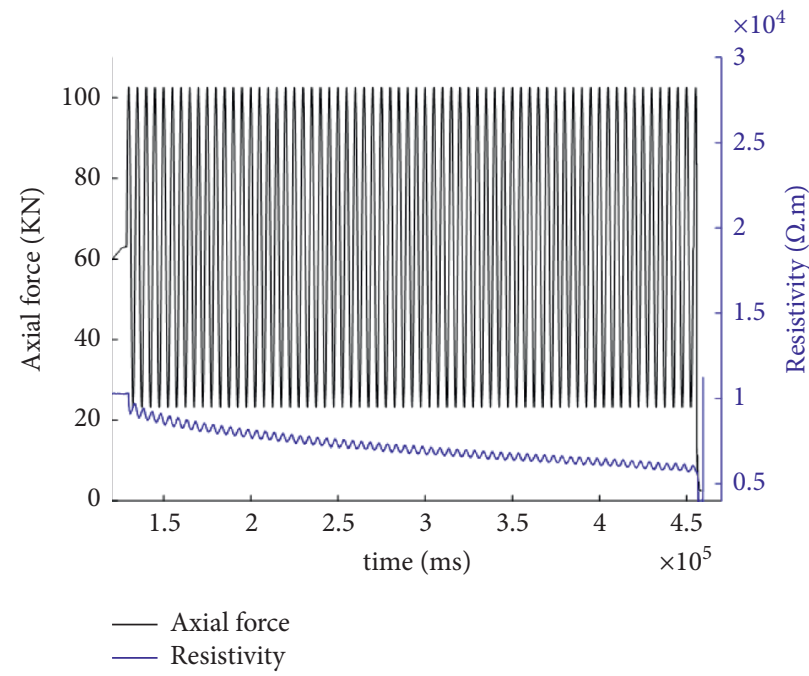

(a)

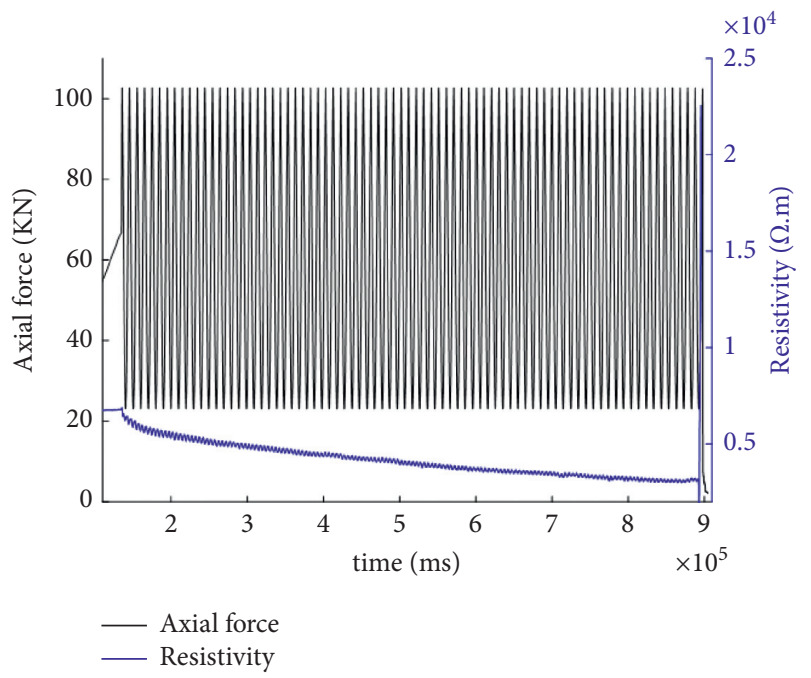

(b)

Figure 8: Resistivity evolution law: (a) evolution law of resistivity of specimen 1; (b) resistivity evolution law of specimen 2.

increased, and the pores closed rapidly, which made the resistivity decrease rapidly. On the other hand, due to the decrease of stress, the compacted pores and microcracks gradually opened, the air entered, and the resistivity increased in the unloading stage. During the unloading stage, the compacted pores and microcracks gradually open up due to the stress reduction, leading to the entry of air and an increase in resistivity.

In general, the change rules of the two specimens were consistent. Due to the high level of load stress, after each cyclic loading and unloading, the specimen yielded and produced plastic residual deformation, including the plastic deformation caused by the pressure sealing of microcracks and the loose particles generated by the convex failure of the microcrack surface. This results in better contact between the mineral particles, between the skeleton and the pore water, and better connectivity of the hydraulic channels after each loading cycle than after the previous cycle. Therefore, the resistivity of the rock specimen tends to decrease as the cyclic loading proceeds. By the last couple of cycles, when the sandstone specimen is on the verge of destruction, the internal cracking accelerates and the contact between the skeletal particles deteriorates, and the rock resistivity shows a gradual increase. By the time the fatigue life of the specimen was reached, the extended microcracks have been penetrated into large macroscopic cracks, the specimen was damaged, and the resistivity increased suddenly $[26,32]$.

\section{Analysis of Sandstone Damage Evolution Law}

Under the action of cyclic loading, the essence of rock damage is the damage process of continuous sprouting, expansion, and penetration of internal cracks. The resistivity and $\mathrm{AE}$ parameters were very sensitive to the changes of crack closure, initiation, and coalescence, but the sensitivity of the two parameters to different loading stages was different. Two kinds of parameters played a complementary role, so it is feasible to combine the two parameters to comprehensively determine the failure process of rock. In this paper, damage mechanics was used to defining the damage variable based on wave-electric field parameters. On this basis, the damage evolution model based on waveelectric field parameters was constructed to analyze the fatigue damage evolution law of sandstone.

4.1. Damage Variables Based on AE Parameters. Yang et al. [33] researched the damage evolution law of rock by triaxial compression test and established a rock damage model based on the cumulative ringing count of AE. The formula was used to define the damage variable $D$ as the ratio of the defect area $A_{d}$ on the material cross section to the total area $A$ of the material cross section [34], and the damage variable $D$ reflected the degree of material degradation.

$$
D=\frac{A_{d}}{A} .
$$

When $D=0$, it was equivalent to the nondestructive state of the material; when $D=1$, it was equivalent to the complete failure state of the material. The larger the $D$ value was, the more serious the material was damaged.

If the cumulative ringing count of $\mathrm{AE}$ was assumed to be $\phi_{m}$ when the whole section area $\mathrm{A}$ of the material was completely destroyed, the AE rate per unit area was

$$
n_{v}=\frac{\phi_{m}}{A}
$$

When the damaged area of the section reached $A_{d}$, the cumulative ringing count is

$$
\begin{aligned}
\phi & =n_{v} A_{d} \\
& =\frac{\phi_{m}}{A} A_{d} .
\end{aligned}
$$


According to equations (1) and (3), the damage variable based on cumulative ringing count can be obtained:

$$
D_{c}=\frac{\phi}{\phi_{m}} \text {. }
$$

Boundary conditions: $\quad N=0, D=0 ; N=N_{F}, D=1$, where $N$ represents the cycle period and $N_{F}$ represents the total cycle period of rock failure.

4.2. Damage Variable Based on Resistivity. The damage process of rock was always accompanied by the closure and propagation of cracks, which were the factors that cause the change of resistivity. Based on Dai's s definition of damage variable by porosity, Li et al. [35] firstly creatively established damage variable based on resistivity by porosity.

We defined damage variable $D_{\varphi}$ based on rock porosity:

$$
D_{\varphi}=\frac{\phi_{0}-\phi}{\phi_{0}-\phi_{s}}
$$

where $\phi_{0}$ is the initial porosity of unloaded rock and $\phi_{s}$ is the porosity of rock failure.

According to Archie formula [8], the resistivity of rock is as follows:

$$
\rho=\frac{a b \rho_{w}}{\phi^{m}} S r^{-n},
$$

where $a, b$ are coefficients related to rock; $\rho_{w}$ is the resistivity of stratigraphic water; $\phi$ is the porosity of the rock materials; $S r$ is the saturability; $m$ is the index of rock cementation; and $n$ is the index of rock saturation.

Based on the definition of saturation,

$$
S r=\frac{V_{w}}{V_{v}} .
$$

For dry rock, unsaturated, its natural water content was very small. Then, assume that the volume of water has not changed during the loading process. The saturation can be defined, after correction, as

$$
S r=\frac{V_{w}}{\phi V}
$$

where $\phi=\left(V_{v} / V\right)$.

Then, the resistivity is

$$
\rho=\frac{a b \rho_{w}}{\phi^{m}}\left(\frac{V_{w}}{\phi V}\right)^{-n} .
$$

In order to increase the applicability of Archie's equation, the trend of rock resistivity evolution is expressed as the ratio of resistivity to initial resistivity:

$$
\frac{\rho}{\rho_{0}}=\left(\frac{\phi_{0}}{\phi}\right)^{m-n} \text {. }
$$

Therefore, we can get the resistivity of rock at any time in the loading process by measuring the porosity of rock. The damage variable $D_{\rho}$ defined on the basis of resistivity ratio can be obtained by adding formula (5) to formula (10):

$$
D_{\rho}=\frac{1-\left(\rho / \rho_{0}\right)^{-(1 / m-n)}}{1-\left(\rho_{S} / \rho_{0}\right)^{-(1 / m-n)}},
$$

where $\rho_{0}$ is the initial resistivity of the material; $\rho_{S}$ is the resistivity when material is damaged; $m$ is the bond index (parameter inversion $m$ is 2.0); and $n$ is the saturation index (the parameter inversion $n$ is 1.33).

In this way, through formulas (5) and (10), the damage variable $D_{\rho}$ based on resistivity was established.

4.3. Comprehensive Damage Variables. First of all, the damage variable-cycle number relationship according to the resistivity and $\mathrm{AE}$ from above was established, respectively, by taking specimen 1 as an example, as shown in Figure 9.

Then, a comprehensive damage variable $D$ was defined according to the complementarity of $D_{\rho}$ and $D_{c}$ in different stages of rock failure, as shown in Figure 10. In the initial cycle stage, $D_{\rho}$ can better characterize the damage deformation process of sandstone, and $D_{\rho}$ was selected to define the comprehensive damage variable $D$. In the accelerated failure stage, $D_{c}$ can better reflect the failure process of sandstone, and $D_{c}$ was selected to define comprehensive damage variable $D$. In fatigue stability stage, the part between the two was taken to define comprehensive damage variable. In this way, comprehensive damage variables $D$ can better reflect the failure process of sandstone under constant-amplitude cyclic loading.

Then, through data fitting, the piecewise expression of the comprehensive damage variable can be obtained as equations (12)-(17):

$$
A A_{1}: D=a_{0}\left(\frac{N}{N_{F}}\right)^{4}+b_{0}\left(\frac{N}{N_{F}}\right)^{3}+c_{0}\left(\frac{N}{N_{F}}\right)^{2}+d_{0} \frac{N}{N_{F}}+e_{0},
$$

$$
\begin{aligned}
a_{0} & =-3596, \\
b_{0} & =1304.5, \\
c_{0} & =-164.56, \\
d_{0} & =9.4655, \\
e_{0} & =0.0088, \\
\left(R^{2}\right. & =0.9877), \\
A_{1} B: D & =a_{1} \frac{N}{N_{F}}+b_{1}, \\
a_{1} & =0.5538, \\
b_{1} & =0.2242, \\
\left(R^{2}\right. & =0.9999),
\end{aligned}
$$




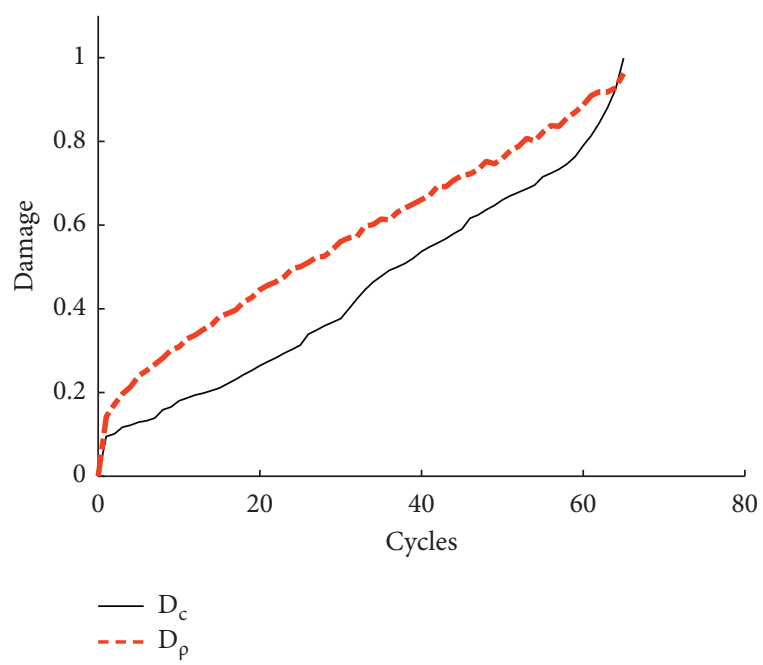

FIgURE 9: Rock's damage variables based on resistivity and AE.

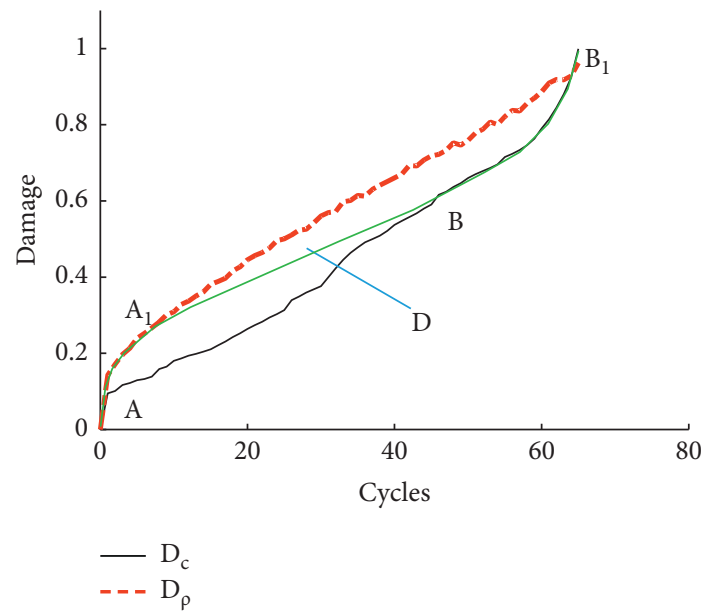

Figure 10: Comprehensive damage variables.

$$
\begin{aligned}
B_{1} B: D & =a_{2}\left(\frac{N}{N_{F}}\right)^{3}+b_{2}\left(\frac{N}{N_{F}}\right)^{2}+c_{2} \frac{N}{N_{F}}+d_{2}, \\
a_{2} & =26.795 \\
b_{2} & =-64.637 \\
c_{2} & =52.49 \\
d_{2} & =-13.664 \\
\left(R^{2}\right. & =0.9968)
\end{aligned}
$$

where $N / N_{F}$ is the cycle ratio.

4.4. Damage Evolution Model. Damage evolution equation based on low cycle fatigue:

$$
D=1-\left[1-\left(\frac{N}{N_{F}}\right)^{1-c}\right]^{1 / b+1} .
$$

The damage evolution equation of sandstone can be obtained by using the comprehensive damage variable proposed above and equation (18) fitted by Origin software:

$$
\begin{aligned}
D & =1-\left[1-\left(\frac{N}{N_{F}}\right)^{0.29}\right]^{0.41}, \\
b & =1.437 \\
c & =0.710 \\
R^{2} & =0.9988
\end{aligned}
$$

The damage constitutive relation of rock under uniaxial compression based on existing studies is

$$
\sigma=E(1-D) \varepsilon
$$

Under uniaxial constant-amplitude cyclic loading, the damage model of sandstone can be obtained as follows:

$$
\sigma=E\left[1-\left(\frac{N}{N_{F}}\right)^{0.29}\right]^{0.41} \varepsilon
$$

It can be seen that the comprehensive damage model established by the combination of resistivity and $\mathrm{AE}$ parameters can well describe the damage process of rock.

\section{Conclusions}

In this paper, an experimental study of sandstone under constant-amplitude cyclic loading was carried out. Under different loading conditions, the two characteristics of $\mathrm{AE}$ and resistivity of sandstone were analyzed, and the damage model was established by combining the two parameters. The research contents of this paper are summarized as follows:

(1) The three stages of fatigue deformation correspond to the evolution of $\mathrm{AE}$ under constant-amplitude cyclic loading conditions: the deformation developed faster and AE activity was stronger in the initial stage. Then, in the fatigue stabilization stage, the deformation developed at a low rate and AE activity weakened. And cracks expand rapidly and AE activity increases suddenly until the rock is damaged in accelerated damage stage. At the same time, most of the AE signals occur near the upper-stress limit.

(2) The evolution trend of rock resistivity with load shows that, on the one hand, the resistivity drops rapidly in the loading stage, and on the other hand, in the unloading stage, it rises rapidly. Overall, the resistivity of sandstone under cyclic loading gradually decreased, until resistivity instantaneously increased when the failure occurs.

(3) Based on the existing theoretical basis, mainly the relationship between rock porosity and resistivity, the damage variable based on resistivity was deduced. Combined with the damage variable established by the cumulative $\mathrm{AE}$ number proposed by 
predecessors, a comprehensive damage variable based on AE parameters and resistivity was established by fitting test data. The comprehensive damage variable can better reflect the damage process of rock. Based on this, under constant-amplitude cyclic loading, the damage model of sandstone was constructed.

\section{Data Availability}

The experimental data used in this study are available from the corresponding author upon request.

\section{Conflicts of Interest}

The authors declare that they have no conflicts of interest.

\section{Acknowledgments}

The authors gratefully acknowledge the financial support from the Natural Science Foundation Project of China (grant no. 51609027), Science and Technology Projects of Department of Transportation of Jiangxi Province (grant no. 2019Q0027), and Chongqing Postgraduate Research Innovation Project, University Level (project no. 2021S0023).

\section{References}

[1] J. Li, Y. Huang, Z. Chen, M. Li, M. Qiao, and M. Kizil, "Particle-crushing characteristics and acoustic-emission patterns of crushing gangue backfilling material under cyclic loading," Minerals, vol. 8, no. 6, p. 244, 2018.

[2] S. Y. Liu, L. Y. Tong, Q. Yu, and L. C. Miao, "Crushable effects on engineering mechanical properties of colliery wastes," Chinese Journal of Geotechnical Engineering, vol. 27, pp. 505-510, 2005.

[3] D. Ma, J. Zhang, H. Duan et al., "Reutilization of gangue wastes in underground backfilling mining: overburden aquifer protection," Chemosphere, vol. 264, no. 1, Article ID 128400, 2021.

[4] D. Ma, H. Duan, J. Liu, X. Li, and Z. Zhou, "The role of gangue on the mitigation of mining-induced hazards and environmental pollution: an experimental investigation," The Science of the Total Environment, vol. 664, pp. 436-448, 2019.

[5] A. Alnedawi, K. P. Nepal, and R. Al-Ameri, "Effect of loading frequencies on permanent deformation of unbound granular materials," International Journal of Pavement Engineering, vol. 22, pp. 1-9, 2019.

[6] W. Hu, Z.-Y. Yin, G. Scaringi, C. Dano, and P.-Y. Hicher, "Relating fragmentation, plastic work and critical state in crushable rock clasts," Engineering Geology, vol. 246, pp. 326-336, 2018.

[7] A. Gheibi and A. Hedayat, "Ultrasonic investigation of granular materials subjected to compression and crushing," Ultrasonics, vol. 87, pp. 112-125, 2018.

[8] L. Obert and W. I. Duvall, "Micro-seismic method of determining the stability of underground openings," Department of the Interior, Washington, DC, USA, 1957.

[9] X. Lei, S. Ma, and S. Ma, "Laboratory acoustic emission study for earthquake generation process," Earthquake Science, vol. 27, no. 6, pp. 627-646, 2014.

[10] L. Yi and D. Feng, "A review of experimental and theoretical research on the deformation and failure behavior of rocks subjected to cyclic loading," Journal of Rock Mechanics and Geotechnical Engineering, 2021.

[11] M. Gernot, C. Denis, and O. Dani, "Sources and characteristics of acoustic emissions from mechanically stressed geologic granular media - a review," Earth-Science Reviews, vol. 112, pp. 97-114, 2012.

[12] X. Lei, "Laboratory acoustic emission study review," in Rock Mechanics and EngineeringVol. 2, CRC Press, Boca Raton, FL, USA, 2017.

[13] P. Rodríguez, P. B. Arab, and T. B. Celestino, "Characterization of rock cracking patterns in diametral compression tests by acoustic emission and petrographic analysis," International Journal of Rock Mechanics and Mining Sciences, vol. 83, pp. 73-85, 2016.

[14] X. Lei, T. Satoh, and O. Nishizawa, "Experimental study on stress-induced pre-failure damage in rocks and its applications to earthquake source-process research based on AE," in Proceedings of the The National Seminar on Non-Destructive Evaluation (NDE), Hyderabad, India, December 2006.

[15] J. Ou, Z. Zhou, Y. Wang et al., "Mechanics and acoustic emission characteristics of marble under uniaxial cyclicloading and unloading conditions," China tungsten industry, vol. 32, no. 6, pp. 34-39, 2017.

[16] K. R. Zhao, Z. Peng, S. H. Ran, D. X. Yang, and T. Y. Teng, "Effect of moisture content on characteristic stress and acoustic emission characteristics of red sandstone," Rock and Soil Mechanics, vol. 42, no. 4, pp. 1-10, 2021.

[17] Y. Jiang, X. Ge, and J. Ren, "Deformation rules and acoustic emission characteristics of rocks in process of fatigue failure," Chinese Journal of Rock Mechanics and Engineering, vol. 23, no. 11, pp. 1810-1814, 2004.

[18] J. Z. Wang, M. Su, and C. Research, "Review of resistivity variation characteristics under load conditions on rock," Journal of Chongqing Jianzhu University: Natural Science Edition, vol. 30, no. 3, pp. 419-423, 2011.

[19] G. E. Archie, "The electrical resistivity log as an aid in determining some reservoir characteristics," Transactions of the AIME, vol. 146, no. 1, pp. 54-62, 1942.

[20] O. A. L. Lima, B. C. Michael, G. N. Geraldo, and N. Sri, “A volumetric approach for the resistivity response of freshwater shaly sandstones," The Journal Geophysics, vol. 70, no. 1, pp. F1-F10, 2005.

[21] T. Masao, Y. Isao, and F. Yoshio, "Anomalous electrical resistivity of almost dry marble and granite under axial compression," Journal of Physics of the Earth, vol. 41, no. 6, pp. 337-346, 1993.

[22] G. Chen and Y. Lin, "Stress-strain-electrical resistance effects and associated state equations for uniaxial rock compression," International Journal of Rock Mechanics and Mining Sciences, vol. 41, no. 2, pp. 223-236, 2004.

[23] W. F. Brace and A. S. Orange, "Electrical resistivity changes in saturated rock under stress," Science, vol. 153, no. 3 743, pp. 1 525-531 526, 1966.

[24] W. Zhang, Q. Sun, S. Zhu, and S. Hao, "The effect of thermal damage on the electrical resistivity of sandstone," Journal of Geophysics and Engineering, vol. 14, no. 2, pp. 255-261, 2017.

[25] C. Wang, Y. Xu, and X. Gao, "Electrical resistivity variation of compressed rock and damage evolution of overburden in coal mine goaf," Coal Engineering, vol. 53, no. 2, pp. 117-121, 2021.

[26] G. Wu, K. Wang, M. Zhao, Z. Nie, and Z. Huang, "Analysis of damage evolution of sandstone under uniaxial loading and unloading conditions based on resistivity characteristics," Advances in Civil Engineering, vol. 2019, Article ID 9286819, 12 pages, 2019. 
[27] K. Wang, X. Li, Z. Huang, and M. Zhao, "Experimental study on acoustic emission and resistivity response of sandstone under constant amplitude cyclic loading," Advances in Materials Science and Engineering, vol. 2021, Article ID 6637200, 13 pages, 2021.

[28] Z. Lin, G. Li, T. Dong et al., "Overview on development of acoustic emission signal analysis technique and processing," Materials Reports, vol. 28, no. 9, pp. 56-60+73, 2014.

[29] X. Ge, Y. Jiang, Y. Lu, and J. Ren, "Testing study on fatigue deformation law of rock under cyclic loading," Chinese Journal of Rock Mechanics and Engineering, vol. 22, no. 10, pp. 1581-1585, 2003.

[30] Q. Zhang, X. Ge, M. Huang, and H. Sun, "Testing study on fatigue deformation law of red-sandstone under triaxial compression with cyclic loading," Chinese Journal of Rock Mechanics and Engineering, vol. 25, no. 3, pp. 473-478, 2006.

[31] Y. Bai, Experimental Research on the Fatigue Property of Salt Rock under Cyclic loading, Chongqing University, Chongqing, China, 2012.

[32] J. Wang, C. Su, and M. Zhao, "Experimental study on resistivity properties of rocks under loading," Geotechnical Investigation \& Surveying, vol. 41, no. 3, pp. 23-26, 2013.

[33] Y. Yang, D. Wang, M. Guo, and B. Li, "Study of rock damage characteristics based on acoustic emission tests under triaxial compression," Chinese Journal of Rock Mechanics and Engineering, vol. 3, no. 1, 104 pages, 2014.

[34] X. Tang, J. Xu, and B. Yan, "A description of rock fatigue evolution using acoustic emission damage variables," Soil Engineering and Foundation, vol. 27, no. 6, pp. 81-83+110, 2013.

[35] S. Li, X. Xu, Z. Liu et al., "Electrical resistivity and acoustic emission response characteristics and damage evolution of sandstone during whole process of uniaxial compression," Chinese Journal of Rock Mechanics and Engineering, vol. 33, no. 1, pp. 14-23, 2014. 